\title{
ERRATUM TO: BANKING AND DEBT CRISES IN EUROPE: THE DANGEROUS LIAISONS?
}

\author{
BY
}

\author{
BERTRAND CANDELON*, FRANZ C. PALM ${ }^{* * * * * *}$
}

Erratum to: De Economist (2010) 158:81-99

DOI: 10.1007/s10645-010-9138-1

The reproduction quality of Figures 5, 6, and 7 was not good enough. The improved and enlarged version is included here.

\footnotetext{
* Corresponding author: Department of Economics, University Maastricht School of Business and Economics, PO BOX 616, MD 6200 Maastricht, The Netherlands, e-mail:b.candelon@maastrichtuniversity.nl

** Department of Quantitative Economics, University Maastricht School of Business and Economics, PO BOX 616, MD 6200 Maastricht, The Netherlands, e-mail:f.palm@maastrichtuniversity.nl

*** CESifo, Munich, Germany
} 

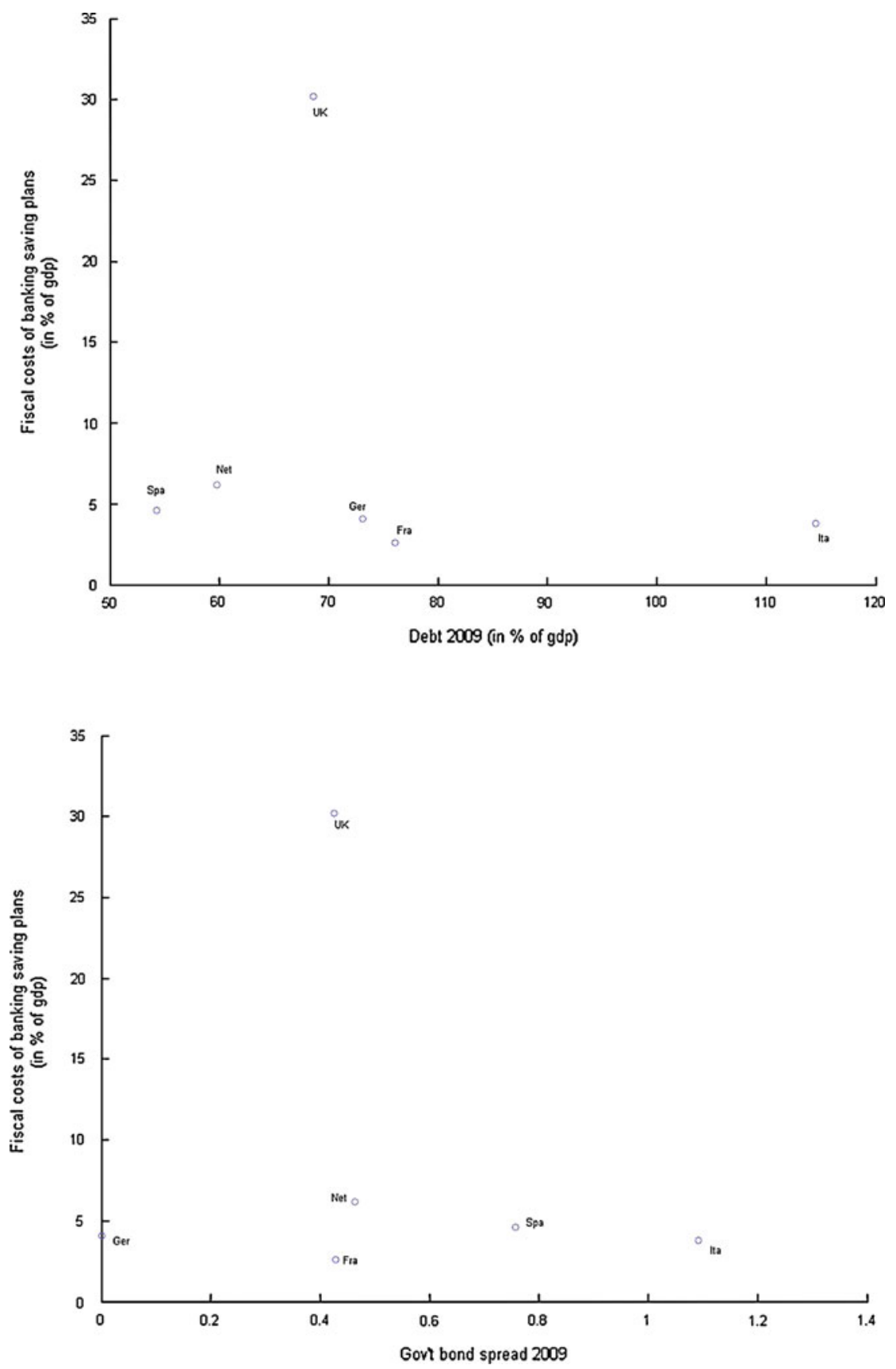

Figure 5 - Banking saving plan and sovereign debt crisis 

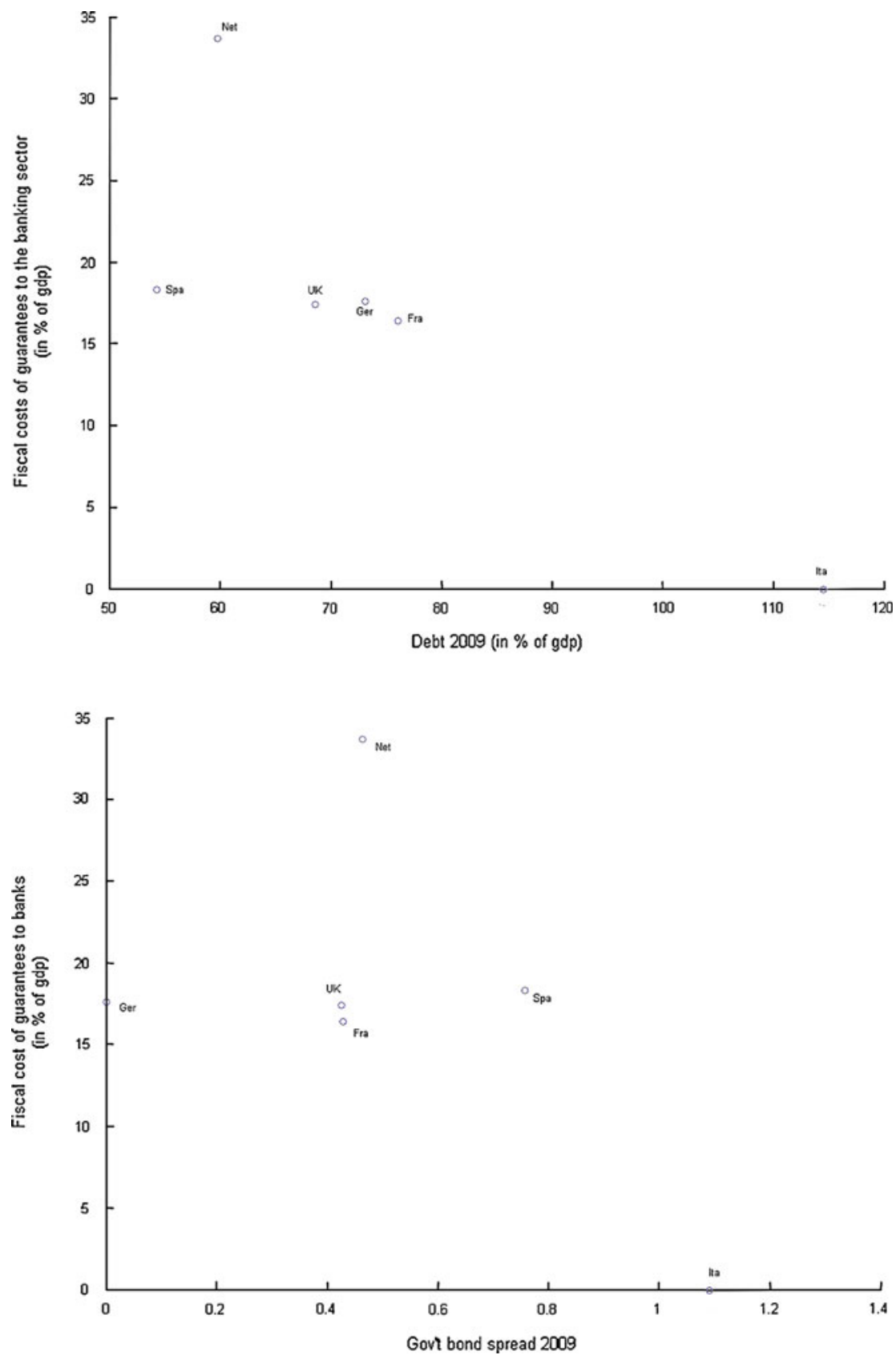

Figure 6 - Guarantee to banks and sovereign debt crisis 

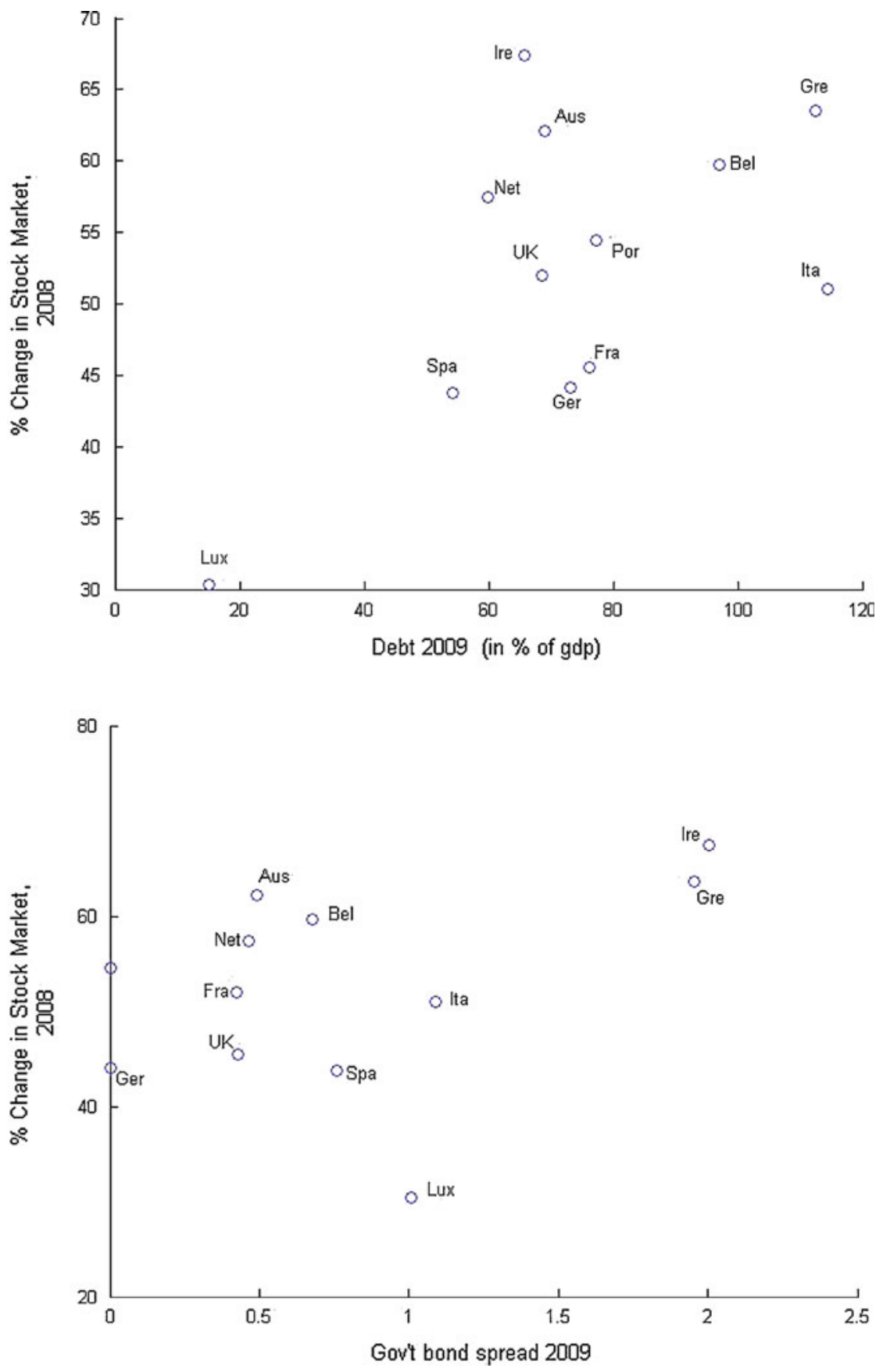

Figure 7 - Stock market growth and sovereign debt crisis 